the faroured possessor of all truth on those subjects which have ever strained the profoundest power of human thought, and relative to which the widest differences have existed among the wisest and most earnest thinkers? Be quite assured that three-fourths of what you are in character is the result of foregone circumstances, and of habits in the forming of which you have had no control; and that if you desire now to shape a little your own character intelligently, you must reconsider every habit, knowing well that had you been reared in another latitude, or in another faith, you would have been quite a different person; and you can scarcely imagine that you have been so fortunate as to have had the best possible training which the globe affords.

In this process, be ready to suspect that if you cherish any view which is shared with you by very few others, and these not the most cultivated minds, that perhaps, indeed not improbably, you are mistaken. On the other hand, if rou have imbibed, without examination, most of the beliefs common to society in its broadest sense, it is equally pro bable, since the masses as a rule are neither very thoughtful nor intelligent, that you may consider further many of those subjects with advantage.

Remember also that while every possible conviction or peculative belief-a range which embraces, therefore, the most diverging or contradictory tenets-is held with equal honesty and tenacity in different portions of the world, there is one thing, and one only, that is common to all good men; there is one great basis of morals and rule of life which has been arrived at by every community sufficiently adranced in culture to form a code of morals, and which, even where not formally acknowledged, is still practically influential: I mean the golden rule, "Do unto others as you would they should do unto you." In cases of doubt as to the proper mode of action in the manifold exigencies of life, as in relation to circumstances in which you have either suffered or committed a wrong, this maxim, althoug. it may not in every known case resolve the difficulty, will nevertheless aid you, and will always promote the right temper in which to form a judgment. In such situations, always reverse the position held by yourself and by the individual with whom you have a controversy, and honestly contemplate the position from that opposite point of view. You smile, perhaps, at ny insisting so much on this truism. You will find it remarkable how much new light may sometimes be gained on a subject, unless you have habitually adopted this mode of treatment. Your way is often at once cleared, and no doubt as to your course of action exists.

Whatever, then, of dogmatic beliefs you have inherited, or may deem important to entertain for yourself, you will, if you attain the character I wish for you, be infinitely more careful to conform your conduct in every particular to this great law of our nature. That it is a great principle deeply interwoven in the constitution of man might be easily shown. That "honesty is the best policy" is proverbial in civilised society, and no day passes, if our eyes are open on human affairs, without showing us how shortsighted are the unbelievers in that great truth. Flourish they may at the first few breaches of the law, but the maxim still is true, and asserts itself sooner or later, either at the cost of a victim, or in the success of an honourable career. The race of life in nine cases out of ten is won by solid qualities-stamina and endurance, and not by fitful spirts which cannot last, and often exhaust the runner before the goal is reached. It was the long, steady, unhurried stroke of the "dark blue" which won that race!

It is the fashion to say that an exhortation to just and honourable conduct, founded on its usually successful issue, presents too low a motive of action, and one which should be despised by a noble mind. I am content to differ, and am ready to accept the stigma unhesitatingly. I reply that my belief in a moral constitution of the world which makes good successful in the long run is in itself a tribute of adniration - a very anthem of praise-to the great design! Further, I affirm that had society not been so constituted, no progress in justice, in benevolence, and in manners could have been possible. The appeal to motives of interest, moreover, has always constituted the final argument of theologians, and its surpassing weight is not to be ignored by the student of human nature.

Thus schooled, you may well afford often to be generous, and to do for others not as well, but much better than they will ever do to you. The complete "man of the world" has a heart, and however deeply he feels the potency of this principle of self-interest which he sees so imperiously governing all around, none better knows than he, not only how good and how wise, but how refreshing it is to cultivate a sentiment, and to give way to the natural impulse of exercising unsought and even undeserved kindness. And yet he knows also how much imprudence is committed under the influence of such feelings. He has often marked the selfishness with which one indulges the exquisite pleasure of being generous, and that here, too, self-denial must sometimes be enforced on behalf of the public good.

I fancy you almost anticipate me now when I say that my observation of the profession during, say, the last twenty years disposes me to suspect that one result of the increasing demand for purely scientific education, and which year by year becomes more imperative, is a certain neglect of that kind of culture which $I$ have recommended.

For men whose lot it is to be settled in the country, and this must, in the nature of things, happen to at least threefourths of you, I think my advice even more desirable, if possible, than for others. The social position of the country practitioner, and therefore his means of exercising beneficial influence, as well as of enjoying life and making the best of it, will depend much more upon the culture I have enjoined than upon his ability to appreciate the latest discovery even in organic chemistry. Not that I underrate that in the least-do not mistake me; I wish you to know it, and to avail yourselves of all that it offers you. But if you are, as you ought to be, and must be by the nature of your profession, provided your training has been complete, the most intelligent, the most capable, and, therefore, the most influential and useful person in that provincial circle of which you are to be a member, it can only be by taking care that your scientifie knowledge is complemented by the possession of what I have described to you as true worldly wisdom. I wish time permitted me to sketch for you, as I have seen him, the beau ideal of the country practitioner, respected by all, the adviser of all; far and away the most useful man in his parish, the most esteemed and loved. Such a man well fulfils the end of life.

I shall now only tell you that it is my belief, after much consideration of the subject, that there is no profession which demands more of its followers, nor to the really successful and honourable prosecution of which larger attainments are requisite, than that upon which you have entered. It is this profound conviction which has determined me to make an attempt, although a very feeble and inadequate one, to impart to you my estimate of the kind of character essential to the achievement of real success. And if I have failed to do so, I shall at least indulge the hope of effecting some good if $I$ succeed in inducing any of you to reflect earnestly on the value and importance of a self-enjoined discipline when entering upon the serious business of life.

\section{ON THE REAPPEARANCE OF RELAPSING OR FAMINE FEVER IN ENGLAND.}

Br CHAS. MURCHISON, M.D., F.R.S.,

PHYSICIAN AND LECTERER ON MIEDICINE TO MIDDLISEX HOSPITAL.

AT the present moment, when we are threatened with an epidemic of relapsing or famine fever, it may be interesting to note the eircumstances under which this disease has reappeared in England after an absence of fourteen years. In my Report of the patients admitted into the London Fever Hospital during the year 1868, published in February, 1869 , I made the following remarks:-

"Not one case of the disease known as relapsing fever, whose prevalence is connected with extreme destitution in a more intimate degree than even that of typhus, and which constituted a great part of the Irish epidemic fever that followed the potato-famine of 1846-7, had been admitted into the hospital for fourteen zears, although in 1851 the number of patients suffering from relapsing fever was greater than that admitted with any other form of fever. But on July 4th, 1868, a girl, aged twenty, was admitted, from 12, Easington's-buildings, Whitechapel, who presented the usual symptoms of the disease. She was of Irish birth, 
but had resided for eight years in London, Four days later, a Polish Jewess, aged thirty-two, who could not speak English, and whose length of residence in London could not be ascertained, was received from 8, Inkhousecourt, Whitechapel, with the same disease; and on July 30 th, a third case was admitted from 9 , Inkhouse-court,* a girl aged fourteen, who had resided in London all her life. In addition to these three cases, it may be added that a girl, aged seven, who had lived in London all her life, was admitted on the same day, and from the same house as the first case, whose illness was registered as 'febricula,' and was probably also relapsing fever; and that on July 6th, a Polish family, consisting of father, mother, and child, were admitted from 8, Inkhouse-court, in a state of extreme debility and destitution, without any marked febrile symptoms, during the seven days that they remained in the hospital. There is no evidence of the recent existence of relapsing fever in Ireland or elsewhere in the British dominions ; but during the past year German physicians have noted the prevalence of relapsing fever in East Prussia and Poland, and have ascribed it to "the great destitution and want of food,' and, since the 1st of last September, seven Polish Jews, six of whom had been lately residing in Whitechapel, had been admitted into the German Hospital in London, suffering from well-marked relapsing fever. $\uparrow$ It is probable, therefore, that in the few instances of relapsing fever observed at the London Fever Hospital, the disease has been contracted from Polish immigrants."

On the 2nd of January, 1868, I received a letter from my friend Dr. Zuelzer, of Berlin, who translated into German my work "On the Continued Fevers of Great Britain," and to whom we are indebted for valuable monographs on the relapsing fever which prevailed in 1864-65 at St. Petersburg, and on the epidemics of typhus and enteric fever which have occurred in Berlin since 1863. In this letter he remarks: "In the last days we are informed that, in the province of East Prussia, relapsing fever and typhus have appeared, caused by the great destitution and want of food." On February 9th, 1868, Professor Virchow delivered a popular lecture on "Famine Fever," for the benefit of the sufferers in East Prussia. Since then I have been informed by Dr. Zuelzer and by Dr. Goltdammer, also of Berlin, that relapsing fever prevailed extensively in Berlin during 1868 and the winter of 1868-69, after an absence from that city of more than half a century. A lare number of patients suffering from it were treated in the Charite Hospital, where many of the nurses and medical officers contracted the disease. Dr. Goltdammer himself had an attack of it, and had the goodness to present me with a table of his temperatures dating from the first day of his attack, and illustrating in a typical manner the peculiar characters of relapsing fever. The attack in his case, it may be observed, did not commence till six days after travelling 200 English miles from Berlin to a locality where relapsing fever was not prevalent; so that the latent period was not less than six days. It is clear, then, that relapsing fever was prevailing extensively in Prussia before it appeared in London; and although neither at the German nor at the Fever Hospitals in London could the first cases be traced directly to importation, the circumstances connected with the first cases observed in the Fever Hospital, coupled with the fact of several destitute Germans being admitted with relapsing fever shortly afterwards into the German Hospital at Dalston, seem to point to the probability of the disease having been imported in the summer of 1868 from Germany. It may be added that I have been unable to discover any evidence of the existence of relapsing fever in Scotland or Ireland, whence on former occasions it has been imported into England. 'There is no mention of it in the recently published reports of the fever hospitals of Glasgow and Cork.

For nine months after the cases admitted into the London Fever Hospital in July, 1868, no other examples of the disease were observed there; but, as already stated, between September 1st, 1868, and February of this year, 7 Polish Jews were admitted with relapsing fever into the German Hospital. But in May of this year the disease was again * Easington's-buildings and Inkhouse-court are about a quarter of a
mile apart. They are both culs-de-sac, very narrow, and densely populated, the former by Irish, and the

+ See the Medical Times and Gazette for WANCET for Febtudry, 1869

$\ddagger$ One of the patients had only been eight days in Eugland before admission into the German Hospital. observed in the Fever Hospital; and within the last few weeks the number of cases has so rapidly increased that there is now every probability of its becoming epidemie. The number of cases admitted in each month since April has been as follows:-

\begin{tabular}{|c|c|c|c|c|}
\hline May & $\ldots$ & $\ldots$ & & .. \\
\hline June & $\ldots$ & $\ldots$ & $\ldots$ & .. \\
\hline July & $\ldots$ & $\ldots$ & $\ldots$ & .. \\
\hline August & $\ldots$ & $\ldots$ & $\ldots$ & .. \\
\hline Septemb & & & $\ldots$ & .. \\
\hline October & (first & lay only & & .. \\
\hline
\end{tabular}

Of the 34 cases admitted in September, 23 were admitted in the last fortnight of the month; in other words, 30 of the 70 cases were admitted during the fifteen days ending with October 1st.

Of the 70 cases, 2 were contracted in the Fever Hospital; the remaining 68 were brought from nineteen of the thirty. six parochial districts of London; but Whitechapel, which furnished the first cases to the German and Fever Hospitals, and Bethnal-green, have together supplied more than onehalf of the cases. None of the patients, however, have come from the same houses, or even streets, as the patients admitted into the Fever or German Hospitals in the summer and autumn of 1868 . The numbers from each district have been as follows:-

\begin{tabular}{lcccr} 
Bethnal-green & $\ldots$ & $\ldots$ & $\ldots$ & 18 \\
Whitechapel & $\ldots$ & $\ldots$ & $\ldots$ & 17 \\
St. Pancras & $\ldots$ & $\ldots$ & $\ldots$ & 5 \\
St. Giles's & $\ldots$ & $\ldots$ & $\ldots$ & 4 \\
Camberwell & $\ldots$ & $\ldots$ & $\ldots$ & 3 \\
Westminster & $\ldots$ & $\ldots$ & $\ldots$ & 3 \\
Lambeth & $\ldots$ & $\ldots$ & $\ldots$ & 2 \\
St. George-the-Martyr... & $\ldots$ & 2 \\
Chelsea & $\ldots$ & $\ldots$ & $\ldots$ & 2 \\
Shoreditch & $\ldots$ & $\ldots$ & $\ldots$ & 2 \\
Islington & $\ldots$ & $\ldots$ & $\ldots$ & 2 \\
St. Luke's & $\ldots$ & $\ldots$ & $\ldots$ & 1 \\
City & $\ldots$ & $\ldots$ & $\ldots$ & 1 \\
St. George's-in-the-East & $\ldots$ & 1 \\
Greenwich & $\ldots$ & $\ldots$ & $\ldots$ & 1 \\
St. Saviour's & $\ldots$ & $\ldots$ & $\ldots$ & 1 \\
St. Olave's & $\ldots$ & $\ldots$ & $\ldots$ & 1 \\
Kensington & $\ldots$ & $\ldots$ & $\ldots$ & 1 \\
Marylebone & $\ldots$ & $\ldots$ & $\ldots$ & 1 \\
London Fever Hospital & $\ldots$ & $\ldots$ & 2 \\
\multicolumn{1}{l|}{} & & & & 70
\end{tabular}

Of the 68 patients, not one was a native of Germany or Scotland; only 5 had been born in Ireland, and 4 of the 5 cases had resided in London for many years before their attack, while the fifth case (admitted in June) had resided in London for three weeks before being seized. The remainder, although in great part of Irish extraction, have been natives of England, and had resided in London for many years or all their lives. With few exceptions, however, they have all been in a deplorable state of destitution; and many of those admitted within the last week have recently returned from hop-picking in Kent, where they have been sleeping in barns and under hedges, and eating unwholesome food-one patient, for instance, stating that he had eaten nothing for weeks except turnips and unripe fruit. The ages of the patients admitted have varied from twelve months to forty-nine years. A child now in the hospital, aged twelve months, has had a well-marked attack of the disease, from which his mother and other members of the family have also suffered; and a nurse who has been in the hospital for nearly twenty years, and who caught the fever in the performance of her duties, is sixty-one years of age. Both this murse and a gentleman doing temporary duty as resident medical officer, and who also contracted relapsing fever, had previously passed through attacks of typhus fever.

The disease has presented all the characteristic features observed in former epidemics. The pyrexia has set in suddenly, the temperature often rising within the first twelve hours to $104^{\circ}$ or $105^{\circ} \mathrm{Fahr}$., and the pulse to 120 or higher, and has been accompanied by severe headache and muscular 
and arthritic pains, sleeplessness, but no impairment of the intellect, painful enlargement of the liver and spleen, in many instances frequent and distressing vomiting, and in some slight jaundice. These symptoms have subsided suddenly, with profuse perspiration, about the fifth, or oftener on the seventh day; in a few hours the pulse may fall from 128 to 84 or 60 , and the temperature from $104^{\circ}$ or $105^{\circ}$ to $99^{\circ} \mathrm{F}$. A little sickness and hepatic tenderness may remain for a day or two, but, as a rule, the patient at once regains his appetite, and may be up and wishing to leare the hospital; when, on the fourteenth day from his first attack, he has an abrupt relapse of all his former symptoms, lasting for three or four days, and subsiding in the same way as before. Quinine in twenty-grain doses has proved useless in preventing this relapse.

Although a much more painful illness than either typhus or enteric fever, the mortality of relapsing fever in all epidemics has been remarkably small, varying from 2 to 5 per cent., and not one of the cases admitted into the Fever Hospital since the reappearance of the disease has hitherto proved fatal. The attack, however, leaves the patient very weak and anæmic, and predisposes him to suffer from other diseases ; and thus, as the spread of relapsing fever and typhus are favoured by like conditions, and both diseases are restricted to the poorest classes of the community, it has been a common observation that an outbreak of relapsing fever has been followed by an increased prevalence of typhus. There are grounds, therefore, for apprehending that during the ensuing winter the poor of London may be visited not only by an epidemic of relapsing fever, but by an increase of typhus, which for some months has been less prevalent in London than at any time during the last eight years.

Wimpole-street, October, 1869.

\section{THE RATIONALE OF THE DECUSSATION OF NERVE-FIBRES IN THE CEREBRO- SPINAL AXIS.}

\section{BY JOHN M. CROMBIE, M.A., M.B.}

Try arrangement whereby one lateral half of the brain presides over the motion and sensation, not of its own, but of the opposite half of the body, appears to be brought about, not for the purposes of the brain itself, but in consequence of the pre-existing arrangement of nerve-fibres in the spinal cord. As far as the function of the brain is concerned, each hemisphere might have acted for its own side of the body; but inasmuch as the sensory nerves of the right side, on approaching that organ, are already ranged on the left side of the cord, it is just as expedient for the right motor nerves to cross over to the left to join them as for them to recross. According to this view, the decussation in the medulla oblongata is intended to compromise the decussation in the spinal cord, it being imperative that the two sets of conductors representing the same side of the body should lie together in the brain. If then, as is here assumed, the first decussation necessitates the second, the point to be determined simply is, what occasions the existence of the first? It is the object of this paper to point out at least one obvious reason why, in the spinal cord, the conductors of sensitive impressions from the right side of the body should be put into immediate communication with the motor nerves of the leet side of the cord, and vice versid.

"Professor Matteucci, nearly twenty years aoro, found that when a nerve going to a muscle is put upon another muscle, a contraction takes place in the first when the second contracts. In this case the nerve recoives an excitation at the time the muscle upon which it lies contracts. The cause of the excitation of the nerve, according to Prof. Matteucci, is a galvanic discharge, which accompanies the muscular contraction......But, whatever be the right explanation, it seems certain that it is some change in the galvanic state of the muscle which causes the excitation of the nerve."

The gist of these observations is, that every time a muscle contracts it generates a stimulus capable of exciting contraction in another muscle, if an appropriate nervous com-

* Brown-Séquard: Physiology of the Central Nervous System, p. 6 . munication exists between them. It further appears, from the researches of Brown-Séquard in the same direction, that the degree of contraction thus secondarily induced varies according to the degree of contraction inducing itbeing always directly proportional. We are entitled to infer from these facts that whenever a muscle or system of muscles contracts, under the influence of the will, a stimulus is generated capable of producing contraction to a definite degree in another muscle or system of muscles, without the further co-operation of the will, if only the medium required for conveying it thither be present. When, therefore, we advance one limb by a voluntary effort, as in commencing to walk, a certain force is engendered by the action of its muscles which is utilisable as a means of exciting a corresponding action, altogether independently of volition, in the muscles of the other limb. In other words, the movement of one foot by an order of the will yields a stimulus in the act which, if transmitted to its fellow, would induce, to a certain extent at least, a similar movement in it. The manifest benefit of an auxiliary force of this kind in sustaining the movements of ordinary locomotion would render the existence of some adaptation in the economy for the purpose of securing it a matter of $a$ priori certainty. But the known disposition of nerve-fibres in the spinal cord is admirably fitted for the attainment of such an end, as will be readily perceived when viewed in this connexion. Let us suppose a soldier is directed to advance his left foot. A volitional stimulus immediately moves the foot into the required attitude, and in doing so elicits a stimulus from the muscles engaged which, according to experiment, is taken up by the sensory nerves distributed in them and carried to the spinal cord. Now, if the motor nerves, through which these conductors discharge their stimulus on arriving there, proceeded to the limb from which the stimulation was derived, the effect would simply be to produce a greater degree of contraction in the muscles of that limb. Such a result would, at best, be useless for the purposes of ordinary progression. But being reflected along the motor nerves of the opposite $\mathrm{limb}$, in consequence of the cross-relationship of motor and sensory nerves in the spinal cord, the stimulus tends to set the right foot agoing. So manifestly is this the case that a counter volition is evidently required to keep the tendency in check when its effects are not immediately wanted. Drill-sergeants, for example, are distressingly sensible of the difficulty of restrainino recruits for a time from the habit, so natural to them, of immediately stepping out when the order is given to advance the foot, instead of waiting, in obedience to the inviolable principles of military propriety, for the solemn word "March !" It is felt to be a relief to be allowed to proceed; and, the march once begun, the one limb appears to alternately reflect to the other so much of the stimulus necessary for the movement, that the will, so long as the muscles remain fresh, seems to be relieved of all concern in the transaction beyond the mere circumstance of suffering it to continue. This not only greatly economises the expenditure of vital force in walking, and takes an otberwise constant burden off the will, but it rould seem to serve in the most direct manner to give regularity and precision to the movements of the limbs, and to preserve the balance of the body. It is just such a provision as is required to assimilate the co-ordination of the moving apparatus on the two sides of the mesial line to the complete action and reaction of a perfectly elastic body. For if the immediately preceding contraction of the muscles of one side genders the stimulus for the immediately subsequent contraction of those of the other, the rhythm thence resulting must be absolute in proportion to the absence of interfering causes. It never is absolute, perhaps as much as anything from the unavoidably controlling influence of the will, which is known to be productive of irregularity and awkwardness whenever it is perceptibly present in guiding the movement. But under the most favourable circumstances, when the muscles are fresh and the will is as much as possible in abeyance, the rhythm displayed by the human body in walking is wonderful, considering the multitude of separate muscles engaged, a defalcation of whose action in any degree would very sensibly detract from the entire result. Of course, there is no actual proof to show that the sensory fibres coming from a particular muscle are in direct continuity with the motor fibres going to the identical muscle on the opposite side; but it clearly appears from an experiment of 